\title{
Toward a Neuro-Cognitive Animal Model of the Cognitive Symptoms of Schizophrenia: Disruption of Cortical Cholinergic Neurotransmission Following Repeated Amphetamine Exposure in Attentional Task-Performing, but Not Non-Performing, Rats
}

\author{
Rouba Kozak ${ }^{1,3}$, Vicente Martinez ${ }^{1,3}$, Damon Young', Holden Brown', John P Bruno ${ }^{2}$ and Martin Sarter*, \\ 'Department of Psychology, University of Michigan, Ann Arbor, MI, USA; 'Department of Psychology, Ohio State University, Columbus, OH, USA
}

\begin{abstract}
Impairments in attentional functions and capacities represent core aspects of the cognitive symptoms of schizophrenia. Attentional performance has been demonstrated to depend on the integrity and activity of cortical cholinergic inputs. The neurobiological, behavioral, and cognitive effects of repeated exposure to psychostimulants model important aspects of schizophrenia. In the present experiment, prefrontal acetylcholine (ACh) release was measured in attentional task-performing and non-performing rats pretreated with an escalating dosing regimen of amphetamine $(\mathrm{AMPH})$ and following challenges with $\mathrm{AMPH}$. In non-performing rats, pretreatment with $\mathrm{AMPH}$ did not affect the increases in ACh release produced by $\mathrm{AMPH}$-challenges. In contrast, attentional task performanceassociated increases in $\mathrm{ACh}$ release were attenuated in $\mathrm{AMPH}$-pretreated and $\mathrm{AMPH}$-challenged rats. This effect of repeated $\mathrm{AMPH}$ exposure on ACh release was already present before task-onset, suggesting that the loss of cognitive control that characterized these animals' performance was a result of cholinergic dysregulation. The findings indicate that the demonstration of repeated AMPH-induced dysregulation of the prefrontal cholinergic input system depends on interactions between the effects of repeated AMPH exposure and cognitive performance-associated recruitment of this neuronal system. Repeated AMPH-induced disruption of prefrontal cholinergic activity and attentional performance represents a useful model to investigate the cholinergic mechanisms contributing to the cognitive impairments of schizophrenia.
\end{abstract}

Neuropsychopharmacology (2007) 32, 2074-2086; doi:I0.I 038/sj.npp. I 30 I352; published online I 4 February 2007

Keywords: amphetamine; attention; acetylcholine; prefrontal cortex; schizophrenia; microdialysis

\section{INTRODUCTION}

As reflected by the NIMH Initiative 'Measurement and Treatment Research to Improve Cognition in Schizophrenia' (MATRICS), the determination of the neuronal abnormalities that underlie the cognitive impairments of schizophrenia and the development of novel pro-cognitive treatments are pressing research objectives. Based on the fundamental role of attentional processes for learning and general cognitive control, attentional dysfunctions have been considered a central and even essential characteristic of schizophrenia (Braff, 1993; Braff and Light, 2004; Braver

* Correspondence: Dr M Sarter, Department of Psychology, University of Michigan, 4032 East Hall, 530 Church Street, Ann Arbor, MI 48I 091043, USA, Tel: + | 734764 6392, Fax: + I 734763 7490,

E-mail: msarter@umich.edu

${ }^{3}$ These authors contributed equally to this work.

Received 13 October 2006; revised and accepted 3 January 2007 et al, 1999; Keefe et al, 2006; McGhie and Chapman, 1961; Nuechterlein et al, 1994; Venables, 1964).

Attention describes the cognitive states and operations that govern the readiness for the detection of changes in the stimulus situation, the selection of such changes over irrelevant 'noise' for further processing, and the management of attentional resources for the detection and processing of competing stimuli. Substantial evidence supports a crucial role of the cortical cholinergic input system in the mediation of attentional functions and capacities (Everitt and Robbins, 1997; Sarter et al, 2001, 2005a). Removal of cortical cholinergic inputs produces persistent impairments in attentional performance. Furthermore, attentional performance is associated with increases in cortical acetylcholine (ACh) release that are not observed in animals performing tasks controlling for the nonattentional aspects of performance (Dalley et al, 2001; Himmelheber et al, 1997, 2000; Kozak et al, 2006; McGaughy et al, 1996, 2000; Passetti et al, 2000; Turchi 
and Sarter, 1997, 2000). The available evidence indicates that the cortical cholinergic input system mediates not one particular aspect of attention but supports a range of attentional abilities, including sustained, selective, and divided attention.

Although reduced muscarinic receptor densities in the cortex of schizophrenics have been reported (Crook et al, 2000, 2001; Hyde and Crook, 2001; Newell et al, 2007; Raedler et al, 2003), the status of cortical cholinergic neurotransmission in schizophrenia remains poorly understood. Owing in part to the lack of methods capable of assessing dynamic aspects of cholinergic dysregulation in humans, the potential contribution of cholinergic dysregulation to the cognitive symptoms of patients is unknown.

Repeated exposure to psychostimulants has long been known to produce psychotogenic effects in humans (Bell, 1965, 1973; Kokkinidis and Anisman, 1981; LeDuc and Mittleman, 1995; McDonald, 1964; O'Flanagan and Taylor, 1950; Snyder, 1973; Snyder et al, 1972; Wallis et al, 1949; Weiner, 1964). Furthermore, the effects of repeated psychostimulant exposure in healthy humans and animals model important neurobiological, behavioral, and cognitive aspects of schizophrenia (Castner and Goldman-Rakic, 1999, 2003; Kapur, 2003; Laruelle, 2000; Lieberman et al, 1997; Robinson and Becker, 1986; Segal et al, 1981; Segal and Janowski, 1978; Strakowski et al, 1997; Yui et al, 1999), including the deficits in sensorimotor gating and attentional processing (Crider et al, 1982; Martinez et al, 2005; Sarter et al, 2005b; Tenn et al, 2003). Furthermore, repeated psychostimulant exposure models the sensitization of the mesolimbic dopamine system that has been demonstrated in never-medicated patients and during psychotic periods (Abi-Dargham et al, 1998; Laruelle, 2000; Laruelle and AbiDargham, 1999; Laruelle et al, 1996, 1999; Strakowski et al, 1997). Based on evidence suggesting close links between the mesolimbic dopamine system and basal forebrain cholinergic neurons (Moore et al, 1999; Neigh-McCandless et al, 2002; Neigh et al, 2004; Zmarowski et al, 2005), abnormal regulation of the cortical cholinergic input system has been hypothesized to represent an integral component of the dysregulated forebrain systems responsible for the cognitive symptoms of schizophrenia (Sarter et al, 2005b). Previous findings indicating psychostimulant exposure-induced alterations in the regulation of basal forebrain cholinergic neurons are consistent with this hypothesis (Martinez et al, 2005; Nelson et al, 2000). However, this evidence does not form the basis for hypotheses describing unidirectional, causal relationships between dysregulated dopaminergic and cholinergic systems. Escalating bidirectional interactions between abnormally regulated mesolimbic projections to the basal forebrain and prefrontal cortex, and aberrant cholinergic recruitment of prefrontal neurons projecting to mesolimbic regions may ultimately be responsible for the disruption of prefrontal-mesolimbic information processing that is widely hypothesized to underlie the cognitive symptoms of schizophrenia. The present focus on the regulation of the prefrontal cholinergic input system is based on the extensive evidence linking this system to fundamental attentional processes.

The present experiment utilized an escalating dosing pretreatment regimen of amphetamine (AMPH) that is known to generate neurobiological and behavioral char- acteristics resembling psychostimulant psychosis (Paulson et al, 1991; Segal and Kuczenski, 1997). This regimen produces lasting psychomotor sensitization without yielding neurotoxicity (Paulson et al, 1991; Paulson and Robinson, 1995; Robinson and Camp, 1987; Robinson et al, 1988). Importantly, psychomotor sensitization, locomotor hyperactivity, or stereotypies are not observed in attentional task-performing rats following the repeated administration of AMPH, perhaps as a result of the constraining of the animals' behavior by the operant and attentional requirements of the task (Martinez et al, 2005). Furthermore, it is important to note that the administration of AMPH-challenges is thought to model the role of stressors in eliciting psychotic episodes, and/or in revealing a sensitized mesolimbic system (Moghaddam, 2002; Robinson and Becker, 1986) that can trigger active disease periods (Lieberman et al, 1997; Ventura et al, 1989; Yui et al, 1999).

The present study was designed to determine the effects of pretreatment and challenge with $\mathrm{AMPH}$ on ACh release in the medial prefrontal cortex (mPFC) in animals performing a task taxing attentional capacities and in animals that did not perform a task. This experiment was guided by the general hypothesis that in order to demonstrate the abnormal regulation of a neurotransmitter system, recruitment of that system, by behavioral and cognitive operations relevant to that system, is required. The results support this hypothesis and indicate that repeated exposure to AMPH disrupts the regulation of cholinergic projections to the prefrontal cortex and thereby cognitive task control. Furthermore, these findings indicate the usefulness of experiments designed to measure the effects of repeated AMPH exposure on cognitive performance and, simultaneously, performance-associated increases in ACh release, as a model for research on the neuronal mechanisms underlying the cognitive symptoms of schizophrenia as well as on the development of novel treatments for the cognitive symptoms of this disorder.

\section{METHODS}

\section{Animals and Animal Housing}

Twenty-four male Fischer-344/Brown-Norway F1 hybrid rats (Harlan Sprague-Dawley, Indianapolis, IN), weighing between 300 and $350 \mathrm{~g}$ at the beginning of behavioral training, were housed individually in a temperature $\left(23^{\circ} \mathrm{C}\right)$ - and humidity (45\%)-controlled environment with a 12:12 light/dark cycle (lights on at 0700 hours). Animals were handled extensively before the beginning of training. Food (Rodent Chow, Harlan Teklad, Madison, WI) was available ad libitum, whereas water was available only during behavioral training as reward (below) as well as for $8 \mathrm{~min}$ in the home cage following daily operant training. Animal care and experimentation were performed in accordance with protocols approved by the University Committee On Use and Care of Animals of the University of Michigan (UCUCA).

\section{Behavioral Training and Testing}

Apparatus. Behavioral training was conducted using 12 operant chambers (Med-Associates, St Albans, VT), each 
enclosed within a sound-attenuating compartment and equipped with three panel lights $(2.8 \mathrm{~W})$, two retractable levers and a water dispenser delivering $30 \mu \mathrm{l}$ water per reward into a cup located between the two levers. A house light $(2.8 \mathrm{~W})$ was located on the rear wall. Signal presentation, lever operation, water delivery, and data collection were controlled by a PC running Med-PC for Windows software (V 4.1.3; Med-Associates).

Task training. Training methods and evidence in support of the validity of performance measures in terms of reflecting sustained attention performance have been previously described (Arnold et al, 2003; McGaughy and Sarter, 1995; Sarter and McGaughy, 1998). It should be noted that the use of this particular task in this experiment does not necessarily imply that performance of specifically this task would uniquely activate the cortical cholinergic input system; rather, this form of attention can be more readily trained and tested in rats when compared with more complicated tasks designed to assess other aspects of attention, such as divided attention (Turchi and Sarter, 1997, 2000).

Training occurred between 08:00 and 18:30 hours 7 days a week. Animals were initially trained to lever press for water in accordance with a modified FR-1 schedule. Following at least three consecutive sessions of over 120 reinforced lever presses, animals advanced to the second stage of task acquisition. Animals were first trained to discriminate between signal ( $1 \mathrm{~s}$ illumination of the central panel light) and non-signal (no illumination) events. Two seconds following the occurrence of a signal or non-signal, both levers were extended into the operant chamber and remained active for $4 \mathrm{~s}$ or until a lever press occurred. During signal trials, a left lever press was scored as a hit, whereas a right lever press was scored as miss. Conversely, during non-signal trials, a right lever press was scored as a correct rejection and a left lever press was scored as a false alarm. Half of all animals were trained to acquire the task using reversed response rules. Hits and correct rejections were rewarded, whereas false alarms and misses were not. During this stage of training, incorrect responses resulted in the initiation of correction trials. During correction trials, the previous trial was repeated up to three times. If an animal continued to respond incorrectly, a forced-choice trial was initiated by presenting the correct lever only following a signal or non-signal event. Correction and forced-choice trials served to facilitate the acquisition of response rules and prevent the development of a side bias.

Once animals achieved at least three consecutive days of stable performance defined as $\geqslant 59 \%$ correct responses to both signal- and non-signal events, they advanced to the third stage of task acquisition. Signal duration was shortened and signals were presented for 25,50 , or $500 \mathrm{~ms}$. The sequence of signal duration and the occurrence of signal and non-signal trials were pseudo-randomized to yield 27 trials per signal duration and 81 non-signal trials. Correction trials and forced trials were discontinued, and the intertrial interval (ITI) was shortened from $12 \pm 3$ to $9 \pm 3 \mathrm{~s}$. As will be further detailed below, measures of performance included the relative number of hits (hits/hits + misses), calculated for each signal length, and the relative number of correct rejections (correct rejections/correct rejections + false alarms). Once animals achieved at least 3 days of stable performance, defined as $\geqslant 70 \%$ hits to $500 \mathrm{~ms}$ signals, $\geqslant 70 \%$ correct rejections, and $\leqslant 50 \%$ omissions to $25 \mathrm{~ms}$ signal), they began training in the final task (see Figure 1). House lights were illuminated throughout the session. This important final modification requires that animals constrain their behavior to maintain persistent orientation toward the intelligence panel. Each session lasted approximately $40 \mathrm{~min}$. The pretreatment regimen was initiated after animals maintained criterion performance ( $\geqslant 70 \%$ hits to $500 \mathrm{~ms}$ signals, $\geqslant 70 \%$ correct rejections, and $\leqslant 20 \%$ omissions) for 3 consecutive days.

Performance measures. Measures of performance included hits, misses, correct rejections, false alarms, and omissions. The relative number of hits and correct rejections was calculated as described above. To obtain an overall index of
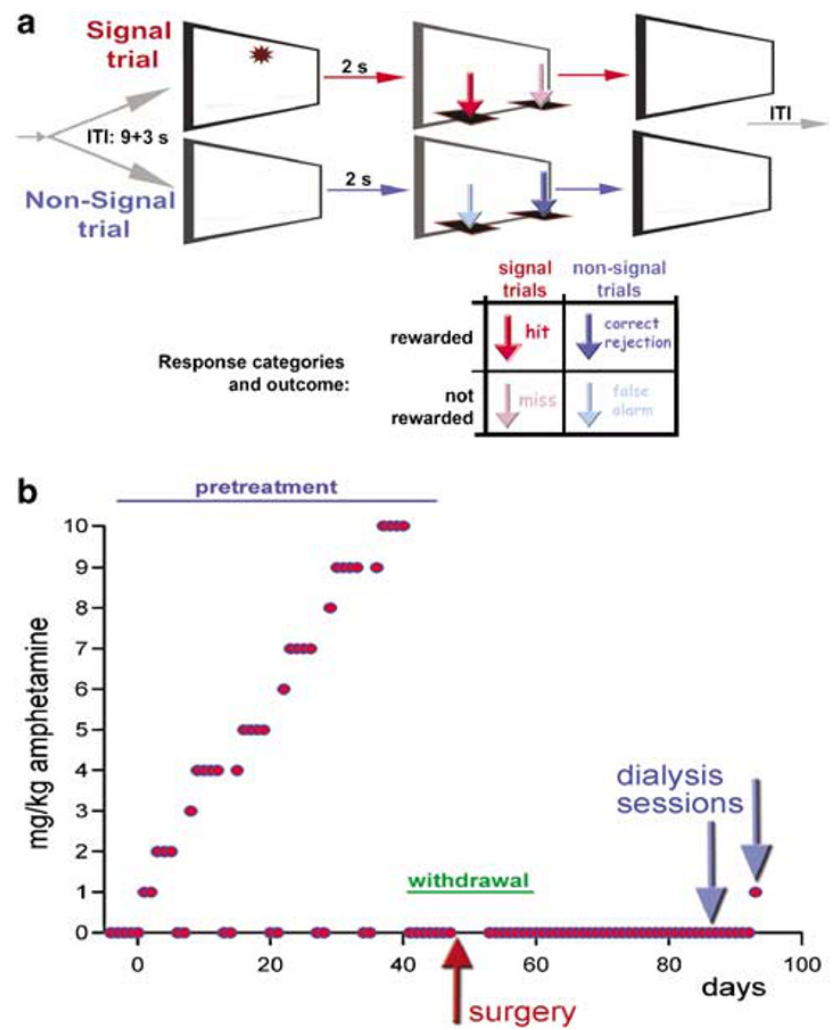

Figure I Top: schematic illustration of the sequences of events and the two trial types of the sustained attention task (a). A session consisted of I 62 signal or non-signal trials. Correct responses in signal trials (hits) and non-signal trials (correct rejections) were rewarded (see arrows), whereas incorrect responses (misses and false alarms, respectively) were not. The ITI was variable to limit the animals' ability to time an event. Bottom: Illustration of the AMPH-pretreatment regimen and the overall timeline of main events including pretreatment, withdrawal period, surgery and the assessment of $\mathrm{AMPH}$-challenges on attentional performance and performance-associated ACh release in the prefrontal cortex. Animals were treated twice a day during the pretreatment phase, before the daily training session and $8 \mathrm{~h}$ later (the ordinate depicts the dose that was given twice daily; each dot depicts one day and dose; see Methods for details). Control animals received vehicle throughout the pretreatment regimen (not shown) and, similar to $\mathrm{AMPH}$-pretreated rats, $\mathrm{AMPH}$-'challenges' following the 'withdrawal' period. Non-performing animals were treated likewise, except that the task was never activated. 


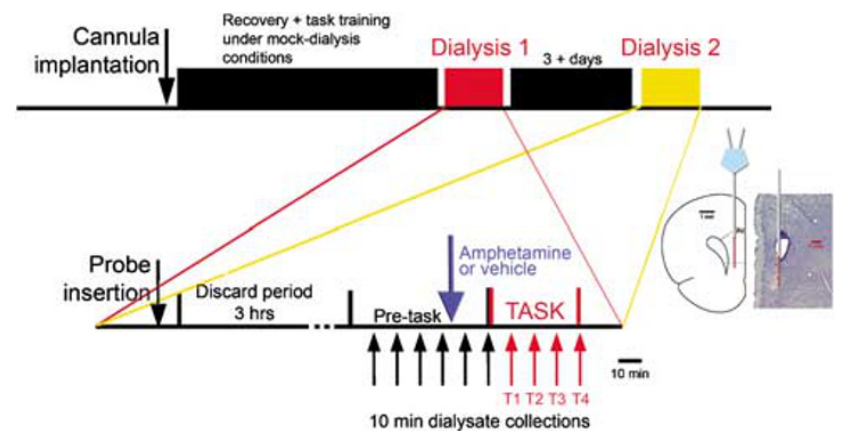

Figure 2 Main sequence of events following surgery (top) and detailed illustration of events during an individual dialysis session (lower line). As detailed in the Methods section, animals were implanted with a guide cannula for the later insertion of a microdialysis probe 7 days following the completion of the pretreatment regimen (see also Figure I). Following a period of subsequent recovery and daily behavioral training under mockdialysis conditions, animals underwent two sessions during which probes were inserted into the prefrontal cortex and perfused. Vehicle or $\mathrm{AMPH}$ challenges were administered during these sessions. During an individual dialysis session, the probe was inserted early in the morning, the animal was placed into the operant chamber, and the probe was connected to syringes and pumps. During the next $3 \mathrm{~h}$, the probe was perfused and dialysates were discarded. The three collections before drug administration were used to determine the stability of ACh efflux and basal ACh efflux. Following two collections after the administration of drug or vehicle, the task was activated and four 10-min samples were collected. The inset shows a representative placement of a microdialysis probe in the prelimbic region (Prl), superimposed over a schematic section (left) and an actual coronal section (probe length reflects approximately the $1 \mathrm{~mm}$ scales inserted in both the schematic and the photomicrograph).

performance that reflects the performance in trials involving signals as well as non-signal events, the vigilance index (VI) was calculated based on the relative number of hits $(\mathrm{h})$ and false alarms (fa) using the formula: $V I=(h-f a) /[2(h+$ $\left.\left.\mathrm{fa})-(\mathrm{h}+\mathrm{fa})^{2}\right]\right)$. This index is comparable to the sensitivity index (SI) (Frey and Colliver, 1973) except that VI is based on the relative number of hits and false alarms, whereas SI is calculated using the probabilities for hits and false alarms. Thus, VI values are not confounded by errors of omission. Values for VI can vary from +1.0 to -1.0 , with +1.0 indicating that all responses were scored as hits or correct rejections, 0 indicating an inability to discriminate between signal and non-signal events, and -1 indicating that all responses to signals were misses and all responses to nonsignals were false alarms. The index was calculated for each signal duration $\left(\mathrm{VI}_{500,50,25}\right)$. Finally, errors of omission were recorded. Performance measures were calculated collectively for the entire session as well as separately for each of four task blocks (10 min each; see Figure 2).

\section{Pretreatment Regimen and Challenges}

After reaching performance criterion, animals were randomly divided into two groups ( $n=7$ each) designated to be pretreated with AMPH or vehicle (saline; SAL). Animals were administered either $d$-AMPH sulfate $(1-10 \mathrm{mg} / \mathrm{kg}$; i.p.; concentrations included salt weight; dissolved in $1.0 \mathrm{ml} / \mathrm{kg}$ of $0.9 \%$ saline; Sigma, St Louis, MO) or saline $(1.0 \mathrm{ml} / \mathrm{kg}$ i.p.) twice per day, with approximately $8 \mathrm{~h}$ separating the two injections (Figure 1). Animals received the first injection at approximately 0800 hours and were placed immediately into the test chambers. Task onset was $20 \mathrm{~min}$ post-injection. Following the completion of the test session, animals were promptly returned to their home cages. The second dose of drug or vehicle was given in the home cage at approximately 16:00 hours. AMPH doses were administered in elevating increments over the course of 40 days (Paulson et al, 1991). All animals were given injections of saline on weekends to mimic the 'runs and crashes' known to foster psychostimulant-induced psychosis (see Figure 1; for references see Introduction). Following AMPH doses of $2 \mathrm{mg} / \mathrm{kg}$ or higher, task performance was disrupted and animals omitted all trials. In order to control for the potentially confounding effects of substantially lower amounts of task practice in AMPH-treated animals, animals treated with vehicle were placed in the testing chambers but not allowed to perform for an equivalent number of sessions during weekdays, whereas AMPH-treated animals received doses $>2 \mathrm{mg} / \mathrm{kg}$ (Martinez et al, 2005). Both saline- and AMPH-treated animals performed the task on weekends.

In our previous experiment employing this AMPH regimen in task-performing animals (Martinez et al, 2005), we found that following termination of the pretreatment regimen, AMPH-treated animals' performance required about 2 weeks of continued training to return to baseline, reflecting the general behavioral depression observed during this period of withdrawal (Paulson et al, 1991). As this experiment was not designed to study aspects of withdrawal, and in order to implant guide cannula (for the later insertion of microdialysis probes) relatively close to the actual microdialysis test sessions, surgery was conducted 7 days into this withdrawal period. The daily testing continued until surgery (below) and resumed following 5 days of post-surgery recovery during which food and water were available ad libitum. All subsequent testing was conducted in operant chambers modified to accommodate the procedures for microdialysis (see below).

The effects of AMPH-challenges were determined following the administration of $1.0 \mathrm{mg} / \mathrm{kg}$ of AMPH. This dose is the first dose given during the pretreatment regimen and was observed earlier not to produce acute effects on attentional performance (Martinez et al, 2005). Likewise, this dose did not affect the performance of saline-pretreated animals when given as a 'challenge' (Martinez et al, 2005). Therefore, significant differences between the effects of $1.0 \mathrm{mg} / \mathrm{kg}$ when given as a challenge to animals pretreated with AMPH or vehicle can be attributed to the differential pretreatment history. Thus, final comparisons were based on data from animals pretreated with SAL or AMPH and challenged with either SAL or AMPH, resulting in four treatment conditions and groups (SAL/SAL; AMPH/SAL; SAL/AMPH; AMPH/AMPH).

\section{Non-Performing Rats}

Non-performing animals $(n=10)$ were handled extensively using procedures identical to task-performing rats, including the daily transport between home cages and operant chambers and the number and the timing of injections of AMPH $(n=6)$ or SAL $(n=4)$. However, the task was never activated for these animals and, as water reward was not delivered, they were not water deprived. Similar to taskperforming animals, non-performing animals underwent 
stereotaxic surgery 7 days following the cessation of pretreatment. Animals were allowed to recover for 5 days and then resumed the handling procedures for the remainder of the withdrawal period. The effects of AMPHor saline-challenges on ACh release were determined $33.6 \pm 6.4$ days $(M ; S E M)$ after completion of the pretreatment period (in order to match the interval that was required for performing rats; see below).

\section{Surgical Methods}

Surgery was performed under aseptic conditions. Initial anesthesia was induced with $4-5 \%$ isoflurane by placing the animal in an anesthetic chamber (Anesco/Surgivet, Waukesha, WI). Gas was carried via oxygen at a flow rate of $0.6 \mathrm{ml} /$ min. Animals were also given a preoperative injection of an antibiotic (Amikacin, $100 \mathrm{mg} / \mathrm{kg}$; s.c.). Heads were shaved using electric clippers and cleaned with $70 \%$ ethanol and iodine tincture. Ophthalmic ointment was applied to lubricate the eyes. Animals were then mounted into a stereotaxic instrument (David Kopf, Tujunga, CA). Isoflurane was administered via a face mask at $1.5-2 \%$ for the duration of surgery. Microdialysis guide cannula $(0.38 \mathrm{~mm}$ o.d.; Sci Pro, Sanborn, NY, USA) were implanted dorsal to the prelimbic region of the right hemisphere at the following coordinates: AP (from Bregma: $2.9 \mathrm{~mm}$, ML: $0.6 \mathrm{~mm}, \mathrm{DV}: 0.6 \mathrm{~mm}$ (from dura). After surgery, rats were returned to their home cages and allowed to recover for 5 days with free access to food and water. Thereafter, the water deprivation schedule resumed and animals were returned to behavioral training until they regained performance criterion (if applicable). Before daily test sessions, the dummy stylets were removed and polyethylene tubing was attached in order to habituate the animals to performing while being dialyzed.

\section{Microdialysis Methods}

Following recovery, animals resumed operant training in chambers modified to accommodate microdialysis procedures. The modified operant chambers used to measure $\mathrm{ACh}$ release in task-performing rats featured a taller recessed water delivery area $(9.0 \times 5.0 \mathrm{~cm}$, height $\times$ width $)$ to allow access for animals with a probe inserted and inlets and outlets attached, and to accommodate the liquid swivels, syringes and pumps outside the chambers. This was performed in order to allow collection of dialysates outside of the chambers without interfering with the animals' ongoing performance.

Furthermore, the length of the test sessions was set to $40 \mathrm{~min}$ to correspond exactly with the timing of four dialysate collections (10 min each). Procedures designed to foster habituation to microdialysis procedures, particularly the tethering during task performance, were initiated at this point. Because of the subsequent requirement for extended pretask microdialysis discard periods $(3 \mathrm{~h})$, the collection of four baseline dialysates, and an additional two dialysates following drug treatment and before task onset (see Figure 2), rats were placed in the operant chambers $240 \mathrm{~min}$ before task onset. The houselight was illuminated for the entire time the animals were in the operant chambers.
After being transferred to the modified operant chambers, animals were retrained to a performance criterion $(\geqslant 60 \%$ hits to $500 \mathrm{~ms}$ signals, $\geqslant 65 \%$ correct rejections, and $\leqslant 20 \%$ omissions for three consecutive sessions). This criterion was more lenient than for the original acquisition (above), because the performance of tethered animals was more variable and slightly impaired relative to the performance of non-tethered animals. As these animals required a relatively large number of sessions to meet criterion performance, on average $34.7 \pm 3.7$ days elapsed between completion of the pretreatment period and the first microdialysis session. Animals were dialyzed at least twice, first following the administration of saline and $6 \pm 1$ days later following the administration of AMPH. Considering evidence suggesting that even a single dose of AMPH produces sensitizing effects (Vanderschuren et al, 1999), the effects of saline'challenges' were always tested first. In the event that dialysis sessions preceded by saline administration did not result in detectable levels of $\mathrm{ACh}$ as a result of probe failure or severed tubing, a maximum of two additional sessions were conducted in order to generate a complete data set for each animal. Repeated insertion of probes over a period of weeks, up to four insertions, was repeatedly demonstrated to generate similar basal ACh release levels (see Results) sensitive to the blocking of voltage-regulated sodium channels with tetrodotoxin (Bruno et al, 1999; Moore et al, 1993, 1995a, b, 1996).

Before insertion of a concentric microdialysis probe into the brain (Model MAB4; membrane o.d.: $0.24 \mathrm{~mm}$; membrane length: $3.0 \mathrm{~mm}$; Sci Pro), probe recovery was determined in vitro by placing the probe into a $1.0 \mathrm{pmol}$ ACh solution and collecting for $10 \mathrm{~min}$. Probes that were used exhibited recoveries of $\geqslant 9 \%$. Probes were perfused at a rate of $2.0 \mu \mathrm{l} / \mathrm{min}$ with artificial cerebrospinal fluid, $\mathrm{pH}$ $6.9 \pm 0.1$, containing the following (in $\mathrm{mM}$ ): $126.5 \mathrm{NaCl}, 27.5$ $\mathrm{NaHCO}_{3}, 2.4 \mathrm{KCL}, 0.5 \mathrm{NA}_{2} \mathrm{SO}_{4}, 0.5 \mathrm{KH}_{2} \mathrm{PO}_{4}, 1.2 \mathrm{CaCl}_{2}, 0.8$ $\mathrm{MgCl}_{2}$, and 5.0 glucose. Note that the perfusion medium did not contain an acetylcholinesterase inhibitor.

Dialysate collections were frozen at $-80^{\circ} \mathrm{C}$ until $\mathrm{ACh}$ contents were determined using high performance liquid chromatography coupled with electrochemical detection (ESA, Chelmsford, MA), using a mobile phase containing $50 \mathrm{mM}$ sodium phosphate. ACh was separated from choline on UniJet microbore analytical column (Bioanalytical Systems Inc. (BASi), West Lafayette, IN) and catalyzed on a post-column solid-phase reactor containing acetylcholinesterase and choline oxidase. ACh was hydrolyzed to acetate and choline, and choline oxidized to hydrogen peroxide and betaine. The amount of hydrogen peroxide corresponding to ACh was then detected using a 'peroxidase-wired' glassy carbon electrode with an applied potential of $-200 \mathrm{mV}$ (Huang et al, 1995). The concentration of ACh was calculated by integrating the area under the peak and fitting this value to a regression line containing values of ACh that were in the expected range of the in vivo dialysates. The detection limit of this system averaged $2 \mathrm{fmol} / 15 \mu \mathrm{l}$.

\section{Histological Verification of Probe Placements}

Within 1 week following the last microdialysis session, animals were given an overdose of sodium pentobarbital 
and underwent cardiac perfusion with $0.1 \mathrm{M}$ of phosphate buffer followed by $4 \%$ buffered formalin. The brains were post-fixed in formalin overnight, and transferred to a $30 \%$ sucrose phosphate buffer solution. Sections $(40 \mu \mathrm{m}$ thick) surrounding the probe and cannula sites were mounted, stained with cresyl violet, and examined for probe placements.

\section{Statistical Methods}

Statistical analyses for performance and dialysis data were conducted using mixed model analysis of variance (ANOVAs). As basal ACh release data did not differ between groups (see Results), the effects of the challenges on ACh release in performing and non-performing rats were conducted based on values expressed as the percent change values from mean basal $\mathrm{ACh}$ release (average of the last three collections before the administration of AMPH or saline). ACh release values were not corrected for probe recovery. To determine drug-induced changes in ACh release in performing rats, a mixed ANOVA on the effects of task (eg two post-drug/pre-task collections $v s$ four taskassociated collections), pretreatment (AMPH or saline), and session (AMPH- or saline-challenge) was conducted and followed, where appropriate by two- and one-way ANOVAs and multiple comparisons. Task performance was analyzed on the basis of overall performance as indicated by VI (see above for calculation). In addition, the numbers of errors of omission were analyzed. The ANOVAs determined the effects of pretreatment (AMPH vs saline), session (AMPHor saline-challenge), and signal duration (500-25 ms) on VI and omissions. Significant main effects and interactions were followed by two- and one-way ANOVAs and Fisher's least significant difference test (LSD) for multiple comparisons. Exact $p$-values are reported for significant results, as was recommended earlier (Greenwald et al, 1996). Statistical analyses were performed using SPSS Version 14.0 for Windows (SPSS Inc., Chicago, IL).

\section{RESULTS}

\section{Histological Findings}

As illustrated in the inset in Figure 2, dialysis probes were placed into the middle layers of the prelimbic region. In most cases, the active membrane extended either dorsally into the anterior cingulate cortex or ventrally into the infralimbic region. Neither baseline release values nor performance- and/or AMPH-induced changes in ACh release systematically differed between these minor variations in placement, and thus evidence obtained from all these placements was used for final analysis.

\section{Effects of Repeated AMPH on ACh Release in Non-Performing Rats}

Basal ACh release did not differ between non-performing animals pretreated with AMPH and vehicle $(\mathrm{F}(1,8)=0.085$; $p>0.05$; Figure 3 ), nor did basal values differ between session (before vehicle-'challenge' or AMPH-challenge; $\mathrm{F}(1,8)=0.006 ; p>0.05)$, and the two variables did not interact significantly $(\mathrm{F}(1,8)=0.09 ; p>0.05)$. Basal ACh
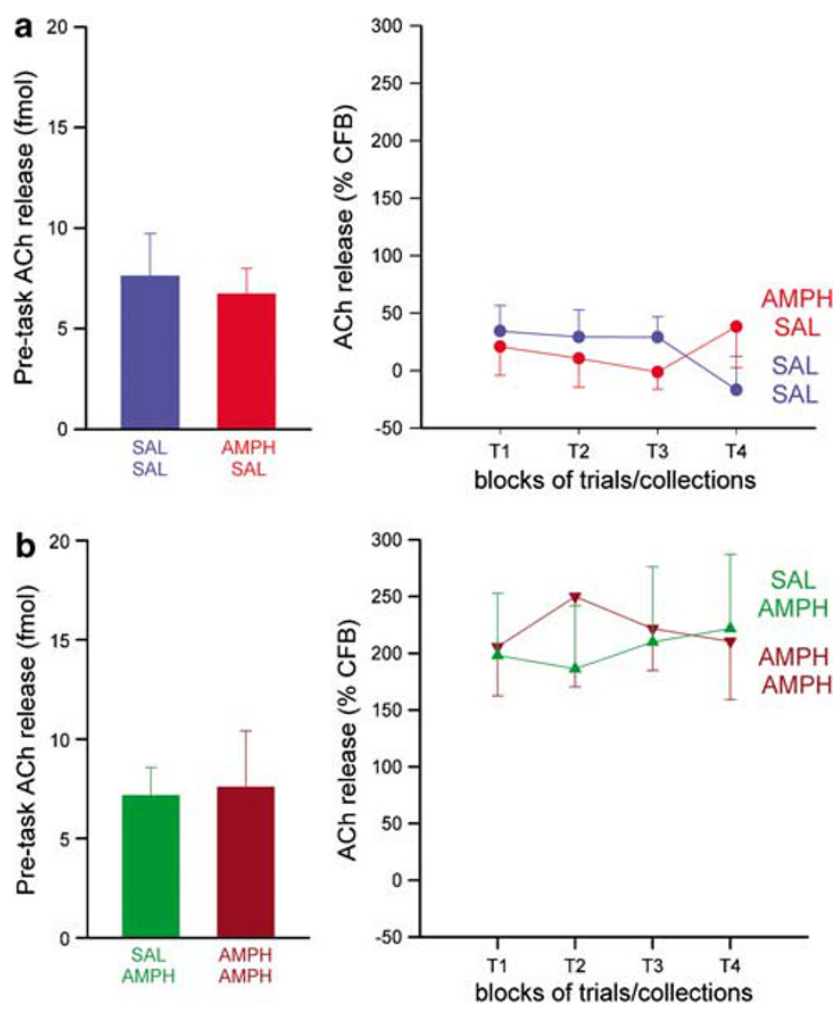

Figure 3 Effects of $\mathrm{AMPH}$-pretreatment and $\mathrm{AMPH}$-challenge on $\mathrm{mPFC}$ ACh release in non-performing rats (M; SEM). The bar graphs indicate absolute release levels (in $\mathrm{fmol} / / 5 \mu \mid$ ) before the administration of saline $(\mathrm{SAL})$ or AMPH. Following saline-'challenges', ACh release levels did not differ between saline- and AMPH-pretreated animals (a; see Results for statistical findings). AMPH-challenges resulted in comparable increases in $\mathrm{ACh}$ release in animals pretreated with SAL or AMPH (b). Thus, in nonperforming animals, the type of pretreatment did not modify the effects of the acute challenges on $\mathrm{ACh}$ release.

release was $7.26 \pm 1.09 \mathrm{fmol} / 15 \mu \mathrm{l}$. Because of the absence of pretreatment effects on basal ACh release, the effects of vehicle- or AMPH-challenge on ACh release were expressed as percent change from baseline.

Compared with the administration of vehicle, the AMPHchallenge resulted in a significant increase in ACh release in both saline and AMPH-pretreated rats (main effect of session: $F(1,8)=28.28 ; p=0.001$ ). The increase in ACh release that resulted from AMPH-challenge did not differ between animals pretreated with vehicle or AMPH (pretreatment: $\mathrm{F}(1,8)=0.07 ; p>0.05$; pretreatment $\times$ session: $\mathrm{F}(1,8)=0.11 ; p>0.05)$. Furthermore, ACh release did not vary over the four collections (T1-T4 in Figure 3), and this variable did not interact with pretreatment or session (all $p>0.05$ ). As illustrated in Figure 3, following saline'challenges', ACh release was $18.06 \pm 15.22 \%$ over baseline (averaged over T1-T4); these values did not differ significantly from baseline values $(\mathrm{F}(1,8)=0.42 ; p>0.05)$. The AMPH-challenges resulted in an increase of $210.66 \pm 35.44 \%$ over baseline $(\mathrm{F}(1,8)=35.13 ; p<0.001)$. Post hoc analyses indicated that AMPH significantly increased ACh release in both groups of animals when compared to the effects of saline-'challenges' (both $p<0.02$ ), and that neither the effects of saline- nor AMPH-challenges differed between animals pretreated with 
saline vs AMPH (both $p>0.05$ ). Thus, the pretreatment history of non-performing animals did not influence the $\mathrm{AMPH}$-challenge-induced increases in ACh release.

\section{Effects of Repeated AMPH on ACh Release in Performing Rats}

Basal ACh release did not differ between animals pretreated with vehicle or AMPH $(\mathrm{F}(1,12)=2.23 ; p>0.05$; Figure 4). Likewise, basal release did not differ before the administration of an AMPH-challenge or vehicle $(F(1,12)=1.63$; $p>0.05$ ) and the two factors (group, session) did not interact significantly $(\mathrm{F}(1,12)=1.62 ; p>0.05)$. Basal ACh release was $7.53 \pm 1.58 \mathrm{fmol} / 15 \mu \mathrm{l}$. Basal release did not differ between non-performing (above) and attentional taskperforming rats $(\mathrm{F}(1,22)=0.00 ; p>0.05)$.
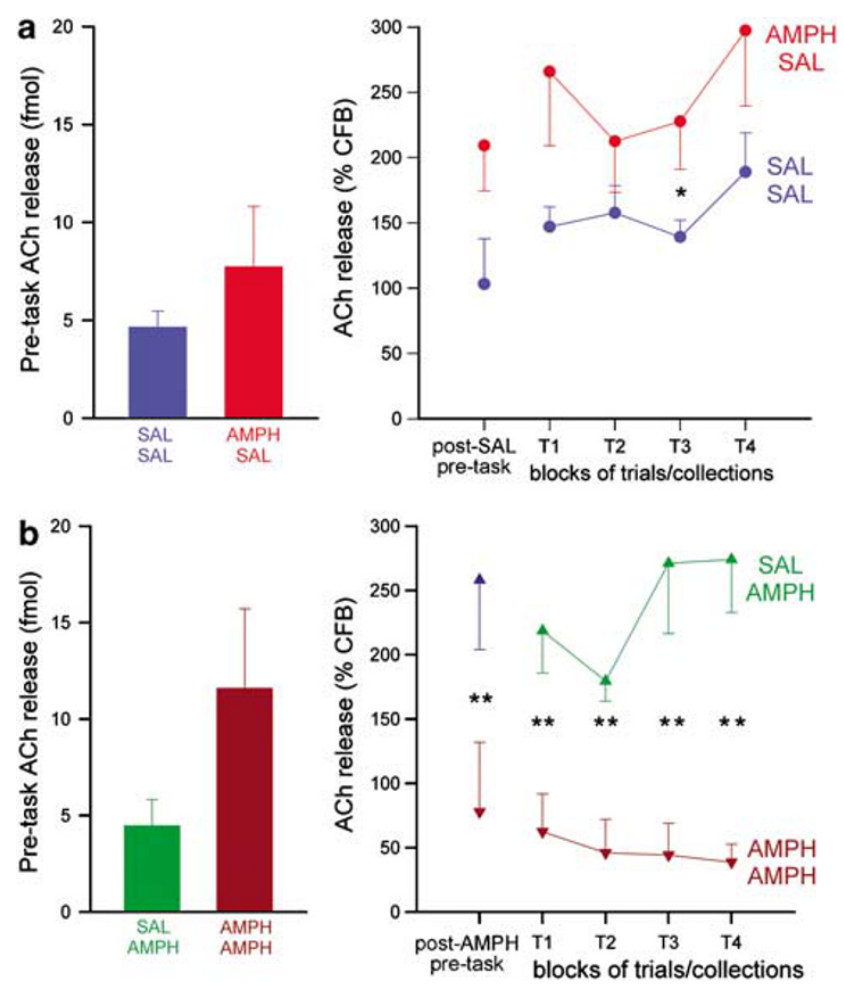

Figure 4 In attentional task-performing rats, the type of pretreatment (saline vs AMPH) determined the effects of the challenge (saline vs AMPH) on ACh release (M; SEM). The bar graphs indicate absolute release levels (in fmol/ I5 $5 \mathrm{l}$ ) before the administration of saline (SAL) (a) or AMPH (b). Absolute levels of ACh release did not differ significantly between the groups or session, and they did not differ from animals that did not perform the task (Figure 3; see Results for statistical findings). AMPH-pretreatment and $\mathrm{AMPH}$-challenge (AMPH/AMPH) resulted in a highly robust attenuation of performance-associated increase in ACh release (b). This effect was already present during the two collections taken before task onset, suggesting that continuous expectation of task onset and performance and/ or the context of performance are sufficient to reveal the interactions between pretreatment and challenge. This observation also rejects the possibility that the attenuation of performance-associated increases in ACh release in $\mathrm{AMPH}$-pretreated and -challenged animals represented merely secondary effects of the disruption of performance $(* p<0.05$; $* * 2 p<0.005$, significant differences between animals pretreated with saline vs $\mathrm{AMPH}$; see Results for ANOVAs).
Effects of AMPH-challenges on performance-associated ACh release. As illustrated in Figure 2, following the administration of drug or vehicle as challenges, two dialysates were collected before task onset. An overall ANOVA on the effects of task-stage (pre-task $v s$ task), pretreatment, and challenge revealed a significant interaction between the effects of pretreatment and challenge $(\mathrm{F}(1,12)=31.63 ; p<0.001)$. However, there was no effect of task-stage and no interactions between task-stage, pretreatment or challenge (all $p>0.05$ ). Thus, the effects of repeated AMPH exposure and AMPH-challenge on ACh release did not differ between the two collections taken before task onset and the four collections taken during task performance (see Figure 4).

Similar to the results from previous experiments (Arnold et al, 2002; Himmelheber et al, 2000; Kozak et al, 2006), performance of the attention task increased ACh release in the mPFC over baseline. In SAL/SAL animals, ACh release increased by $158.28 \pm 18.49 \%$ over basal ACh levels during the performance of the task $(\mathrm{F}(1,6)=66.98 ; p<0.001$; see Figure 4). The performance-associated increase in $\mathrm{mPFC}$ ACh release is comparable to the increase observed previously in animals performing this task and using similar microdialysis conditions, including the absence of an acetylcholinesterase inhibitor (Kozak et al, 2006).

The effects of the AMPH-challenges differed significantly between groups of rats pretreated with SAL vs AMPH (pretreatment $\times$ challenge: $\mathrm{F}(1,12)=30.74 ; p<0.0001$; main effect of challenge: $\mathrm{F}(1,12)=6.14 ; p=0.03$; main effect of pretreatment: $\mathrm{F}(1,12)=3.00 ; p>0.05$; the factor time (T1-T4) did not produce a main effect and did not interact with group and session; all $p>0.05$ ). Figure 4 illustrates that AMPH-challenges in animals pretreated with AMPH (AMPH/AMPH) resulted in the attenuation of performanceassociated increases in ACh release. Several post hoc comparisons further substantiated this result.

The acute administration of AMPH in SAL-pretreated rats did not affect the elevated levels of ACh release observed in animals performing this task (SAL/SAL vs SAL/AMPH; $\mathrm{F}(1,6)=3.88 ; p>0.05)$. In contrast, the acute administration of, or the challenge with, AMPH in animals that were pretreated also with AMPH resulted in a significant attenuation of ACh release levels when compared with animals pretreated with SAL (SAL/AMPH vs AMPH/AMPH $(\mathrm{F}(1,12)=29.62 ; p<0.0001)$. Multiple comparisons indicated that all data points (T1-T4) differed significantly by pretreatment (all $p<0.004$; Figure 4, lower graph). Averaged over all time points, performance-associated ACh release in SAL/AMPH animals was $235.93 \pm 27.47 \%$ over pretask baseline and $47.89 \pm 24.42 \%$ in AMPH/AMPH rats. The attenuation of ACh release levels in AMPH/AMPH animals was also revealed by the within-subject comparison (AMPH/SAL $v s$ AMPH/AMPH; $\mathrm{F}(1,6)=40.83 ; p=0.001)$.

The attenuated levels of ACh release observed in performing AMPH/AMPH rats did not differ significantly from release levels measured at baseline (before task onset and before drug treatment $(\mathrm{F}(1,6)=2.65 ; p>0.05)$. Moreover, a post hoc comparison between ACh release levels in AMPH/AMPH animals over all three phases (baseline, postdrug/pre-task, during performance) indicated that ACh release levels in these animals never changed from baseline $(\mathrm{F}(2,12)=0.79 ; p>0.05)$. 
Finally, in animals pretreated with AMPH and dialyzed following vehicle-'challenge' (AMPH/SAL; Figure 4), performance-associated ACh release was significantly higher than in animals pretreated and 'challenged' with vehicle (SAL/SAL; $\mathrm{F}(1,12)=5.34 ; p=0.04$; averaged over all time points: saline-pretreated: $158.28 \pm 18.49 \%$ over baseline; AMPH-pretreated: $250.92 \pm 18.44 \%$ ). Multiple comparisons indicated that release during T3 was significantly higher in animals pretreated with AMPH $(\mathrm{F}(1,12)=5.20 ; p=0.042$; the effect neared significance during $\mathrm{T} 1 ; \mathrm{F}(1,12)=4.10$, $p=0.06$; Figure 4 , top graph).

\section{Effects of Repeated AMPH on Performance}

Baseline performance before the administration of challenges. During the pretreatment period, administration of escalating doses of AMPH (Figure 1b) increasingly disrupted the animals' performance. During drug-free weekends, performance partially recovered. The pattern of the performance during the 40-day AMPH-pretreatment period and during the subsequent 2-week withdrawal period corresponded with the evidence described previously (Martinez et al, 2005). Before the challenge with AMPH or vehicle, the performance of all animals as measured by VI remained impaired relative to the pretreatment baseline $(\mathrm{F}(1,12)=5.05 ; p=0.04$; pretreatment baseline, $\mathrm{VI}$ averaged over all signal durations: $0.24 \pm 0.03$; prechallenge baseline: $0.12 \pm 0.03$; see Figure 1 for timeline and Methods for additional details). Importantly, the performance of AMPHpretreated rats did not differ from saline-pretreated rats before the administration of the challenges $(\mathrm{F}(1,12)=0.01$; $p>0.05$ ), confirming that the relatively low level of performance at this point was not a result of AMPHpretreatment but of the testing conditions, particularly the tethering procedures required to conduct microdialysis in task-performing animals. The number of trials omitted remained low and did not differ from pretreatment baseline levels $(\mathrm{F}(1,12)=0.02 ; p>0.05$; pretreatment baseline: $12.1 \pm 6.0 \%$ trials omitted/session; prechallenge baseline: $9.0 \pm 1.8 \%)$.

Performance following AMPH-challenges. The analysis of the effects of AMPH-challenges on performance (VI) indicated a significant interaction between the effects of pretreatment, session and signal duration $(\mathrm{F}(2,24)=5.27$; $p=0.01$ ). Figure 5 depicts VI scores individually for the four treatment conditions and each signal duration. Post hoc analyses were conducted to identify the nature of this interaction. First, as was expected, the administration of AMPH as a challenge in SAL-pretreated rats (SAL/AMPH) did not affect VI (SAL/SAL vs SAL/AMPH; $\mathrm{F}(1,6)=0.39$; $p>0.05)$. Likewise, pretreatment with AMPH alone did not affect performance (SAL/SAL vs AMPH/SAL; $\mathrm{F}(1,12)=0.28$; $p>0.05)$. In contrast, the AMPH-challenge in AMPHpretreated rats resulted in a significant decrease in performance compared with the administration of SAL in AMPH-pretreated rats (AMPH/SAL vs AMPH/AMPH; $\mathrm{F}(1,6)=7.50 ; p=0.03)$. Thus, interactions between the effects of pretreatment and challenge with AMPH were responsible for the disruption of performance.

Figure 5 also illustrates the role of signal duration as a factor in the significant overall interaction. One-way
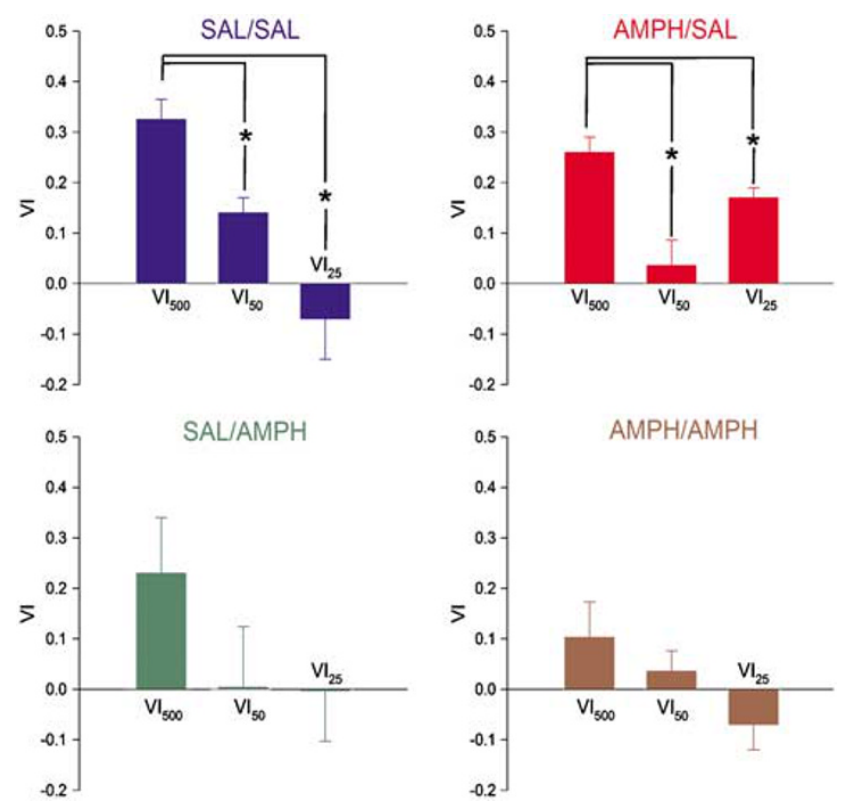

Figure 5 Effects of $\mathrm{AMPH}$-pretreatment and $\mathrm{AMPH}$-challenge on overall attentional performance as indicated by the $\mathrm{VI}$ (M; SEM). As a result of performing under dialysis conditions, including the tethering of the animals, performance was variable and levels of performance were relatively low when compared with the performance before surgery. However, AMPH-challenges resulted in significantly lower levels of performance in $\mathrm{AMPH}$-pretreated animals when compared to the effects of AMPH in saline-pretreated rats. Furthermore, in contrast to SAL/SAL and AMPH/SAL rats (* $p<0.05$; multiple comparisons using LSD tests and conducted on the basis of significant ANOVAs), the depressed levels of performance of AMPH/AMPH animals did not depend on signal duration. The performance in SAL/AMPH animals appeared to remain dependent on signal duration; however, data variability prevented statistical significance $(p=0.07)$

ANOVAs indicated significant effects of signal duration on performance in SAL/SAL $(\mathrm{F}(2,12)=16.51 ; p=0.003)$ and AMPH/SAL rats $(\mathrm{F}(2,12)=9.33 ; p=0.004$; see Figure 5 for multiple comparisons). As indicated in Figure 5, in SAL/AMPH animals, data variability prevent the demonstration of a significant effect of signal duration on VI $(\mathrm{F}(2,12)=3.48 ; p=0.07)$, whereas the performance of AMPH/AMPH rats was depressed and varied between +0.1 and -0.1 for all signal durations $(F(2,12)=2.92$; $p>0.05)$. Thus, pretreatment and challenge with AMPH abolished signal duration-dependent performance; this effect is reflected in the overall significant interaction between the effects of pretreatment, challenge, and signal duration reported above.

A similar interaction between these three factors was found in the analysis of hits $(\mathrm{F}(2,24)=4.41 ; p=0.02)$, but not correction rejections $(\mathrm{F}(1,12)=1.11 ; p=0.31)$, indicating that the effects on VI were largely due to effects of the animals' ability to detect signals. This finding is consistent with the selective impairment in signal trial performance observed following removal of the cortical cholinergic input system (McGaughy et al, 1996).

Finally, AMPH-challenges did not affect the animals' errors of omission $(\mathrm{F}(1,12)=1.57 ; p=0.24)$. Omission rates remained generally low (5.54 \pm 0.76 omissions/session, averaged over all four groups and both test sessions). 


\section{DISCUSSION}

The present results indicate that in animals habituated to testing and microdialysis conditions but that did not perform the attentional task, pretreatment with an escalating dosing regimen of AMPH did not alter the effects of $\mathrm{AMPH}$-challenges on prefrontal ACh release. In contrast, in rats performing the attentional task, such a challenge profoundly attenuated the increases in ACh release normally observed in animals performing this task-but only in animals that were pretreated with AMPH. Furthermore, task performance was disrupted in AMPH/AMPH animals. Based on post-drug and pretask ACh release values, the disruption of performance in AMPH/AMPH animals is concluded to represent a result of the attenuation of prefrontal cholinergic activity. These results suggest that the effects of repeated AMPH exposure on the regulation of cholinergic neurotransmission in the MPFC depend on the level of recruitment of the cholinergic system. Below, empirical limitations and interpretational complexities will be discussed, followed by an evaluation of the significance of these findings for research on the neurobiology of sensitized cognitive impairments and animal models of schizophrenia.

The present results have implications for the understanding of the relationships between ACh release and levels of attentional performance. Previous experiments indicated that increases in the demands on attentional performance, resulting from long-task periods or pharmacological challenges on performance, as opposed to increases in performance levels, correlate with increases in cortical ACh release in task-performing animals (Kozak et al, 2006; Passetti et al, 2000). This evidence corresponds with the hypothesis that increases in $\mathrm{mPFC} \mathrm{ACh}$ release above normal performance-associated levels mediate the recruitment of the 'anterior attention system' and the resulting implementation of top-down mechanisms that counteract the performance decrements triggered by challenging conditions (Sarter et al, 2006). Based on this hypothesis, the augmented increases in ACh release observed in AMPH/ SAL rats, when compared with SAL/SAL animals, may reflect the greater demands on attentional effort required to maintain normal attentional performance. Thus, AMPH/ SAL animals were able to perform at control levels but required abnormally high levels of $\mathrm{mPFC}$ cholinergic activity to maintain performance.

The present evidence suggests that AMPH-pretreatment and AMPH-challenge disrupts attentional performanceassociated increases in $\mathrm{MPFC} \mathrm{ACh}$ release and therefore impaired the animals' ability to employ information concerning the presence or absence of a signal to guide the selection and execution of a response. The finding that following saline or AMPH-challenges, pretask ACh release levels did not differ significantly from ACh release levels during task performance suggests that continuous task performance, the expectation of performance and task onset, and/or being placed in the performance context, are sufficient to reveal the consequences of AMPH-pretreatment. Moreover, this finding supports the view that following repeated AMPH exposure in task-performing rats, AMPH-challenges disrupt the normal recruitment of cholinergic inputs to the PFC and therefore results in the loss of cognitive control. In contrast, the results do not support the alternative view that repeated $A M P H$, via unknown mechanisms, abolished cognitive task control and that the low levels of ACh release were merely secondary to the behavioral/cognitive effects of repeated AMPH exposure.

Previous studies demonstrated that the performance of operant schedules not involving explicit demands on attention do not produce significant increases in cortical ACh release, or produce increases that are substantially lower than those associated with attentional performance. For example, cortical ACh release in rats performing a fixed interval $9 \mathrm{~s}$ schedule of reinforcement increased only by about $50 \%$ over baseline, despite a lever-pressing rate that was almost 10 -fold the rate observed in sustained attention task-performing rats (Arnold et al, 2002). Likewise, operant procedures controlling for the effects of reward rate and the sensory effects of stimuli indicated that these variables do not account for the increases in ACh release observed in attentional task-performing rats (Dalley et al, 2001; Himmelheber et al, 1997). As the performance in noncognitive procedures does not yield the levels of cholinergic activity observed in attentional task-performing animals, the interactions between recruitment of the cholinergic system and repeated psychostimulant exposure demonstrated in the present experiment would not be expected in animals performing tasks that do not tax cognitive functions.

In AMPH/AMPH animals, VI scores varied around zero across all signal durations (Figure 5). A VI score of zero indicates a loss of the ability to discriminate between signal and non-signal trails. That is, responses in signal and non-signal trials reached chance level and the animals' performance was no longer controlled by the presence or absence of a signal. Therefore, the performance of these animals no longer involved attentional processes and the processing of stimulus-response rules. Levels of ACh release in $\mathrm{AMPH} / \mathrm{AMPH}$ animals performing the attention task (present experiment) were similar to ACh release levels observed in rats performing simple operant procedures not involving cognitive operations (references above). This observation is consistent with the conclusion that in AMPH/ $\mathrm{AMPH}$ rats, cognitive task control was abolished. Indeed, ACh release in AMPH/AMPH rats did not increase significantly beyond pretask baseline. Thus, both the behavioral data and the ACh release levels support the conclusion that as a result of the pretreatment and challenge with AMPH, the animals' ability to utilize the presence or absence of signals to guide the responses was drastically impaired or, in other words, cognitive task control was disrupted.

As the pretreatment history of the animals did not modulate the effects of AMPH-challenges in non-performing animals, the present evidence provides a rather stark illustration of the view that the effective demonstration of abnormal regulation of a neuronal system requires recruitment of this system by, for example, demands on relevant behavioral or cognitive functions. This view contrasts with the widespread practice of assessing drug effects on neurotransmitter release, or with the status of neurotransmitter systems in animal models, in animals that remain passive or even anesthetized, and in the absence of 
recruitment of the neuronal system of interest (Sarter et al, 2007).

The mechanisms underlying such drastically different modulation of the cortical cholinergic input system in response to repeated $\mathrm{AMPH}$ exposure remain a subject of speculation. In non-performing but extensively habituated animals, repeated AMPH-induced increases in ACh release could reflect a purely pharmacological effect, due primarily to the release of norepinephrine (Rothman et al, 2001; Vanderschuren et $a l, 2003$ ) and dopamine (Robinson et al, 1988), both of which are capable of stimulating cholinergic neurons in the basal forebrain (Arnold et al, 2001; Berntson et al, 2003a, b; Knox et al, 2004; Momiyama and Sim, 1996; Napier et al, 1991).

In contrast, the recruitment of prefrontal cholinergic inputs in task-performing animals is thought to be mediated via direct prefrontal projections to the basal forebrain as well as via multi-synaptic circuits involving the nucleus accumbens and perhaps also the amygdala (Holland et al, 2000; Lee et al, 2006; Neigh-McCandless et al, 2002; Sarter et al, 2001, 2005a; Zaborszky, 1997, 2002; Zahm, 2000). Together with evidence demonstrating the disruption of the prefrontal modulation of accumbens neurons following repeated psychostimulant exposure (Goto and Grace, 2005), the present findings suggest that repeated AMPH-exposure disrupts such telencephalic innervation of basal forebrain cholinergic neurons and thus, prefrontal ACh release. A range of neuronal mechanisms could be responsible for such a disruption, including abnormalities in glutamatergic and dopaminergic neurotransmission in prefrontal and mesolimbic regions (Giorgetti et al, 2001; Lu and Wolf, 1999; Peterson et al, 2006; Prasad et al, 1995) as well as structural reorganization of prefrontal and mesolimbic neurons (Crombag et al, 2005; Robinson and Kolb, 2004).

As the administration of AMPH as a challenge was necessary to reveal the cholinergic and cognitive consequences of the pretreatment with AMPH, it can be speculated that these consequences were a result of interactions between increases in noradrenergic and dopaminergic neurotransmission and the recruitment of the cholinergic system by cognitive task performance. Importantly, this conclusion does not imply that the dysregulatory consequences of repeated psychostimulant exposure remain restricted to monoaminergic systems; rather, the current results indicate that increases in noradrenergic/dopaminergic systems are necessary to reveal the cholinergic and cognitive consequences of prior psychostimulant exposure. As discussed earlier (Sarter et al, 2005b), the administration of such challenges is thought to model the role of stressors in the initiation of active disease periods. Therefore, the cholinergic dysregulation and disruption of cognitive performance following the pretreatment and challenge with AMPH may primarily serve as a model of the active and deteriorative disease stage (Lieberman et al, 1997). In addition, however, the results indicate that AMPH-pretreatment alone (AMPH/SAL) affects performance-related regulation of ACh release, as higher levels of ACh release were required to maintain normal performance levels in these animals.

As pointed out in the Introduction, the effects of repeated AMPH exposure model essential neurobiological and behavioral/cognitive aspects of schizophrenia. The present results indicate that repeated AMPH exposure causes a fundamental loss of cognitive task control. Such failure of cognitive control has been proposed to form a general basis for the diverse cognitive symptoms of schizophrenia (Braver et al, 1999). Therefore, the effects of repeated AMPH exposure on attentional performance and performance-associated $\mathrm{ACh}$ release appear to form a useful model for further investigations on the cholinergic mechanisms underlying the cognitive impairments of schizophrenia. Furthermore, as ongoing experiments indicate the sensitivity of this animal model in terms of detecting the pro-cognitive effects of drug treatments (Martinez et al, 2006), this model may serve as a tool for research on the role of cholinergic mechanisms mediating the beneficial cognitive effects of treatments, and also for the detection of such treatments.

\section{ACKNOWLEDGEMENTS}

Rouba Kozak is now at Pfizer Pharmaceuticals (Ann Arbor), and Holden Brown is at the University of Illinois (Chicago). The authors' research was supported by PHS Grants MH 063114, NS37026 (MS, JPB), MH057436 (JPB, MS) and KO2 MH01072 (MS). Damon Young was supported by a Predoctoral Fellowship from the Ford Foundation and Vicente Martinez by an Interdisciplinary Research Training Grant in Substance Abuse (T32 DA007267-12; University of Michigan Substance Abuse Research Center; UMSARC).

\section{REFERENCES}

Abi-Dargham A, Gil R, Krystal J, Baldwin RM, Seibyl JP, Bowers M et al (1998). Increased striatal dopamine transmission in schizophrenia: confirmation in a second cohort. Am J Psychiatry 155: 761-767.

Arnold HM, Bruno JP, Sarter M (2003). Assessment of sustained and divided attention in animals. In: Crawley JN, Gerfen CR, Rogawski MA, Sibley DR, Skolnick P, Wray S (eds). Current Protocols in Neuroscience. John Wiley \& Sons: New York. pp 8.5E.1-8.5E.13.

Arnold HM, Burk JA, Hodgson EM, Sarter M, Bruno JP (2002). Differential cortical acetylcholine release in rats performing a sustained attention task versus behavioral control tasks that do not explicitly tax attention. Neuroscience 114: 451-460.

Arnold HM, Fadel J, Sarter M, Bruno JP (2001). Amphetaminestimulated cortical acetylcholine release: role of the basal forebrain. Brain Res 894: 74-87.

Bell DS (1965). Comparison of amphetamine psychosis and schizophrenia. Br J Psychiatry 111: 701-707.

Bell DS (1973). The experimental reproduction of amphetamine psychosis. Arch Gen Psychiatry 29: 35-40.

Berntson GG, Sarter M, Cacioppo JT (2003a). Ascending visceral regulation of cortical affective information processing. Eur $\mathrm{J}$ Neurosci 18: 2103-2109.

Berntson GG, Shafi R, Knox D, Sarter M (2003b). Blockade of epinephrine priming of the cerebral auditory evoked response by cortical cholinergic deafferentation. Neuroscience 116: 179-186.

Braff DL (1993). Information processing and attention dysfunctions in schizophrenia. Schizophr Bull 19: 233-259.

Braff DL, Light GA (2004). Preattentional and attentional cognitive deficits as targets for treating schizophrenia. Psychopharmaco$\log y$ (Berlin) 174: 75-85. 
Braver TS, Barch DM, Cohen JD (1999). Cognition and control in schizophrenia: a computational model of dopamine and prefrontal function. Biol Psychiatry 46: 312-328.

Bruno JP, Sarter M, Moore Arnold H, Himmelheber AM (1999). In vivo neurochemical correlates of cognitive processes: methodological and conceptual challenges. Rev Neurosci 10: 25-48.

Castner SA, Goldman-Rakic PS (1999). Long-lasting psychotomimetic consequences of repeated low-dose amphetamine exposure in rhesus monkeys. Neuropsychopharmacology 20: 10-28.

Castner SA, Goldman-Rakic PS (2003). Amphetamine sensitization of hallucinatory-like behaviors is dependent on prefrontal cortex in nonhuman primates. Biol Psychiatry 54: 105-110.

Crider A, Solomon PR, McMahon MA (1982). Disruption of selective attention in the rat following chronic $d$-amphetamine administration: relationship to schizophrenic attention disorder. Biol Psychiatry 17: 351-361.

Crombag HS, Gorny G, Li Y, Kolb B, Robinson TE (2005). Opposite effects of amphetamine self-administration experience on dendritic spines in the medial and orbital prefrontal cortex. Cereb Cortex 15: 341-348.

Crook JM, Tomaskovic-Crook E, Copolov DL, Dean B (2000). Decreased muscarinic receptor binding in subjects with schizophrenia: a study of the human hippocampal formation. Biol Psychiatry 48: 381-388.

Crook JM, Tomaskovic-Crook E, Copolov DL, Dean B (2001). Low muscarinic receptor binding in prefrontal cortex from subjects with schizophrenia: a study of Brodmann's areas $8,9,10$, and 46 and the effects of neuroleptic drug treatment. Am J Psychiatry 158: 918-925.

Dalley JW, McGaughy J, O’Connell MT, Cardinal RN, Levita L, Robbins TW (2001). Distinct changes in cortical acetylcholine and noradrenaline efflux during contingent and noncontingent performance of a visual attentional task. J Neurosci 21: 4908-4914.

Everitt BJ, Robbins TW (1997). Central cholinergic systems and cognition. Annu Rev Psychol 48: 649-684.

Frey PW, Colliver JA (1973). Sensitivity and responsivity measures for discrimination learning. Learn Motiv 4: 327-342.

Giorgetti M, Hotsenpiller G, Ward P, Teppen T, Wolf ME (2001). Amphetamine-induced plasticity of AMPA receptors in the ventral tegmental area: effects on extracellular levels of dopamine and glutamate in freely moving rats. J Neurosci 21: 6362-6369.

Goto Y, Grace AA (2005). Dopamine-dependent interactions between limbic and prefrontal cortical plasticity in the nucleus accumbens: disruption by cocaine sensitization. Neuron 47: 255-266.

Greenwald A, Gonzalez R, Harris R, Guthrie D (1996). Effects sizes and p-values: what should be reported and what should be replicated. Psychophysiology 33: 157-183.

Himmelheber AM, Sarter M, Bruno JP (1997). Operant performance and cortical acetylcholine release: role of response rate, reward density, and non-contingent stimuli. Cogn Brain Res 6: 23-36.

Himmelheber AM, Sarter M, Bruno JP (2000). Increases in cortical acetylcholine release during sustained attention performance in rats. Cogn Brain Res 9: 313-325.

Holland PC, Han JS, Gallagher M (2000). Lesions of the amygdala central nucleus alter performance on a selective attention task. J Neurosci 20: 6701-6706.

Huang T, Yang L, Gitzen J, Kissinger PT, Vreeke M, Heller A (1995). Detection of basal acetylcholine in rat brain microdialysate. J Chromatogr B Biomed Appl 670: 323-327.

Hyde TM, Crook JM (2001). Cholinergic systems and schizophrenia: primary pathology or epiphenomena? J Chem Neuroanat 22: 53-63.

Kapur S (2003). Psychosis as a state of aberrant salience: a framework linking biology, phenomenology, and pharmacology in schizophrenia. Am J Psychiatry 160: 13-23.
Keefe RS, Bilder RM, Harvey PD, Davis SM, Palmer BW, Gold JM et al (2006). Baseline neurocognitive deficits in the CATIE schizophrenia trial. Neuropsychopharmacology 31: 2033-2046.

Knox D, Sarter M, Berntson GG (2004). Visceral afferent bias on cortical processing: role of adrenergic afferents to the basal forebrain cholinergic system. Behav Neurosci 118: 1455-1459.

Kokkinidis L, Anisman H (1981). Amphetamine psychosis and schizophrenia: a dual model. Neurosci Biobehav Rev 5: 449-461.

Kozak R, Bruno JP, Sarter M (2006). Augmented prefrontal acetylcholine release during challenged attentional performance. Cereb Cortex 16: 9-17.

Laruelle M (2000). The role of endogenous sensitization in the pathophysiology of schizophrenia: implications from recent brain imaging studies. Brain Res Rev 31: 371-384.

Laruelle M, Abi-Dargham A (1999). Dopamine as the wind of the psychotic fire: new evidence from brain imaging studies. $J$ Psychopharmacol 13: 358-371.

Laruelle M, Abi-Dargham A, Gil R, Kegeles L, Innis R (1999). Increased dopamine transmission in schizophrenia: relationship to illness phases. Biol Psychiatry 46: 56-72.

Laruelle M, Abi-Dargham A, van Dyck CH, Gil R, D'Souza CD, Erdos J et al (1996). Single photon emission computerized tomography imaging of amphetamine-induced dopamine release in drug-free schizophrenic subjects. Proc Natl Acad Sci USA 93: 9235-9240.

LeDuc PA, Mittleman G (1995). Schizophrenia and psychostimulant abuse: a review and re-analysis of clinical evidence. Psychopharmacology (Berlin) 121: 407-427.

Lee HJ, Youn JM, O MJ, Gallagher M, Holland PC (2006). Role of substantia nigra-amygdala connections in surprise-induced enhancement of attention. J Neurosci 26: 6077-6081.

Lieberman JA, Sheitman BB, Kinon BJ (1997). Neurochemical sensitization in the pathophysiology of schizophrenia: deficits and dysfunction in neuronal regulation and plasticity. Neuropsychopharmacology 17: 205-229.

Lu W, Wolf ME (1999). Repeated amphetamine administration alters AMPA receptor subunit expression in rat nucleus accumbens and medial prefrontal cortex. Synapse 32: 119-131.

Martinez V, Garetz R, Bernshausen M, Sarter M (2006). Subchronic administration of haloperidol or clozapine attenuates attentional impairments in animals pretreated with amphetamine. Society for Neuroscience Annual Meeting. Atlanta. Abstracts \# 749.716.

Martinez V, Parikh V, Sarter M (2005). Sensitized attentional performance and Fos-immunoreactive cholinergic neurons in the basal forebrain of amphetamine-pretreated rats. Biol Psychiatry 57: 1138-1146.

McDonald RL (1964). Iatrogenic amphetamine psychosis. Am J Psychiatry 120: 1200-1201.

McGaughy J, Everitt BJ, Robbins TW, Sarter M (2000). The role of cortical cholinergic afferent projections in cognition: impact of new selective immunotoxins. Behav Brain Res 115: 251-263.

McGaughy J, Kaiser T, Sarter M (1996). Behavioral vigilance following infusions of 192 IgG-saporin into the basal forebrain: selectivity of the behavioral impairment and relation to cortical AChE-positive fiber density. Behav Neurosci 110: 247-265.

McGaughy J, Sarter M (1995). Behavioral vigilance in rats: task validation and effects of age, amphetamine, and benzodiazepine receptor ligands. Psychopharmacology (Berlin) 117: 340-357.

McGhie A, Chapman J (1961). Disorders of attention and perception in early schizophrenia. Br J Med Psychol 34: 103-117.

Moghaddam B (2002). Stress activation of glutamate neurotransmission in the prefrontal cortex: implications for dopamineassociated psychiatric disorders. Biol Psychiatry 51: 775-787.

Momiyama T, Sim JA (1996). Modulation of inhibitory transmission by dopamine in rat basal forebrain nuclei: activation of presynaptic D1-like dopaminergic receptors. J Neurosci 16: 7505-7512. 
Moore H, Fadel J, Sarter M, Bruno JP (1999). Role of accumbens and cortical dopamine receptors in the regulation of cortical acetylcholine release. Neuroscience 88: 811-822.

Moore H, Sarter M, Bruno JP (1993). Bidirectional modulation of stimulated cortical acetylcholine release by benzodiazepine receptor ligands. Brain Res 627: 267-274.

Moore H, Sarter M, Bruno JP (1995a). Bidirectional modulation of cortical acetylcholine efflux by infusion of benzodiazepine receptor ligands into the basal forebrain. Neurosci Lett 189: 31-34.

Moore H, Stuckman S, Sarter M, Bruno JP (1995b). Stimulation of cortical acetylcholine efflux by FG 7142 measured with repeated microdialysis sampling. Synapse 21: 324-331.

Moore H, Stuckman S, Sarter M, Bruno JP (1996). Potassium, but not atropine-stimulated cortical acetylcholine efflux, is reduced in aged rats. Neurobiol Aging 17: 565-571.

Napier TC, Simson PE, Givens BS (1991). Dopamine electrophysiology of ventral pallidal/substantia innominata neurons: comparison with the dorsal globus pallidus. J Pharmacol Exp Ther 258: 249-262.

Neigh GN, Arnold HM, Rabenstein RL, Sarter M, Bruno JP (2004). Neuronal activity in the nucleus accumbens is necessary for performance-related increases in cortical acetylcholine release. Neuroscience 123: 635-645.

Neigh-McCandless G, Kravitz BA, Sarter M, Bruno JP (2002). Stimulation of cortical acetylcholine release following blockade of ionotropic glutamate receptors in nucleus accumbens. Eur $J$ Neurosci 16: 1259-1266.

Nelson CL, Sarter M, Bruno JP (2000). Repeated pretreatment with amphetamine sensitizes increases in cortical acetylcholine release. Psychopharmacology (Berlin) 151: 406-415.

Newell KA, Zavitsanou K, Jew SK, Huang XF (2007). Alterations of muscarinic and GABA receptor binding in the posterior cingulate cortex in schizophrenia. Prog Neuropsychopharmacol Biol Psychiatry 31: 225-233.

Nuechterlein KH, Dawson ME, Green MF (1994). Informationprocessing abnormalities as neuropsychological vulnerability indicators for schizophrenia. Acta Psychiat Scand 384: 71-79.

O'Flanagan PM, Taylor RB (1950). A case of recurrent psychosis associated with amphetamine addiction. J Mental Sci 96: 1033-1036.

Passetti F, Dalley JW, O'Connell MT, Everitt BJ, Robbins TW (2000). Increased acetylcholine release in the rat medial prefrontal cortex during performance of a visual attentional task. Eur J Neurosci 12: 3051-3058.

Paulson PE, Camp DM, Robinson TE (1991). Time course of transient behavioral depression and persistent behavioral sensitization in relation to regional brain monoamine concentrations during amphetamine withdrawal in rats. Psychopharmacology (Berlin) 103: 480-492.

Paulson PE, Robinson TE (1995). Amphetamine-induced timedependent sensitization of dopamine neurotransmission in the dorsal and ventral striatum: a microdialysis study in behaving rats. Synapse 19: 56-65.

Peterson JD, Wolf ME, White FJ (2006). Repeated amphetamine administration decreases D1 dopamine receptor-mediated inhibition of voltage-gated sodium currents in the prefrontal cortex. J Neurosci 26: 3164-3168.

Prasad BM, Sorg BA, Ulibarri C, Kalivas PW (1995). Sensitization to stress and psychostimulants. Involvement of dopamine transmission versus the HPA axis. Ann NY Acad Sci 771: 617-625.

Raedler TJ, Knable MB, Jones DW, Urbina RA, Gorey JG, Lee KS et al (2003). In vivo determination of muscarinic acetylcholine receptor availability in schizophrenia. Am J Psychiatry 160: 118-127.

Robinson TE, Becker JB (1986). Enduring changes in brain and behavior produced by chronic amphetamine administration: a review and evaluation of animal models of amphetamine psychosis. Brain Res 396: 157-198.
Robinson TE, Camp DM (1987). Long-lasting effects of escalating doses of $d$-amphetamine on brain monoamines, amphetamineinduced stereotyped behavior and spontaneous nocturnal locomotion. Pharmacol Biochem Behav 26: 821-827.

Robinson TE, Jurson PA, Bennett JA, Bentgen KM (1988). Persistent sensitization of dopamine neurotransmission in ventral striatum (nucleus accumbens) produced by prior experience with (+)-amphetamine: a microdialysis study in freely moving rats. Brain Res 462: 211-222.

Robinson TE, Kolb B (2004). Structural plasticity associated with exposure to drugs of abuse. Neuropharmacology 47(Suppl 1): 33-46.

Rothman RB, Baumann MH, Dersch CM, Romero DV, Rice KC, Carroll FI et al (2001). Amphetamine-type central nervous system stimulants release norepinephrine more potently than they release dopamine and serotonin. Synapse 39: 32-41.

Sarter M, Bruno JP, Parikh V (2007). Abnormal neurotransmitter release in behavioral and cognitive disorders: toward concepts of dynamic and function-specific dysregulation. Neuropsychopharmacology (in press).

Sarter M, Gehring WJ, Kozak R (2006). More attention must be paid: the neurobiology of attentional effort. Brain Res Rev 51: 155-160.

Sarter M, Givens B, Bruno JP (2001). The cognitive neuroscience of sustained attention: where top-down meets bottom-up. Brain Res Rev 35: 146-160.

Sarter M, Hasselmo ME, Bruno JP, Givens B (2005a). Unraveling the attentional functions of cortical cholinergic inputs: interactions between signal-driven and top-down cholinergic modulation of signal detection. Brain Res Rev 48: 98-111.

Sarter M, McGaughy J (1998). Assessment of sustained and divided attention in rats: aspects of validity. Psychopharmacology (Berlin) 138: 260-262.

Sarter M, Nelson CL, Bruno JP (2005b). Cortical cholinergic transmission and cortical information processing following psychostimulant-sensitization: implications for models of schizophrenia. Schizophr Bull 31: 117-138.

Segal DS, Geyer MA, Schuckit MA (1981). Stimulant-induced psychosis: an evaluation of animal methods. In: Youdim $\mathrm{MBH}$, Lovenberg W, Sharman DF, Lagnado JR (eds). Essays in Neurochemistry and Neuropharmacology, Vol 5. Wiley: Sussex, UK. pp 95-129.

Segal DS, Janowski DS (1978). Psychostimulant-induced behavioral effects: possible models of schizophrenia. In: Lipton MA, DiMascio A, Killam KF (eds). Psychopharmacology: A Generation of Progress. Raven Press: New York. pp 1113-1124.

Segal DS, Kuczenski R (1997). An escalating dose 'binge' model of amphetamine psychosis: behavioral and neurochemical characteristics. J Neurosci 17: 2551-2566.

Snyder SH (1973). Amphetamine psychosis: a 'model' schizophrenia mediated by catecholamines. Am J Psychiatry 130: 61-67.

Snyder SH, Aghajanian GK, Matthysse S (1972). Prospects for research on schizophrenia. V. Pharmacological observations, Drug-induced psychoses. Neurosci Res Program Bull 10: 430-445.

Strakowski SM, Sax KW, Setters MJ, Stanton SP, Keck Jr PE (1997). Lack of enhanced response to repeated $d$-amphetamine challenge in first-episode psychosis: implications for a sensitization model of psychosis in humans. Biol Psychiatry 42: 749-755.

Tenn CC, Fletcher PJ, Kapur S (2003). Amphetamine-sensitized animals show a sensorimotor gating and neurochemical abnormality similar to that of schizophrenia. Schizophr Res 64: 103-114.

Turchi J, Sarter M (1997). Cortical acetylcholine and processing capacity: effects of cortical cholinergic deafferentation on crossmodal divided attention in rats. Cogn Brain Res 6: 147-158. 
Turchi J, Sarter M (2000). Cortical cholinergic inputs mediate processing capacity: effects of 192 IgG-saporin-induced l esions on olfactory span performance. Eur J Neurosci 12: 4505-4514.

Vanderschuren LJ, Beemster P, Schoffelmeer AN (2003). On the role of noradrenaline in psychostimulant-induced psychomotor activity and sensitization. Psychopharmacology (Berlin) 169: 176-185.

Vanderschuren LJ, Schmidt ED, De Vries TJ, Van Moorsel CA, Tilders FJ, Schoffelmeer AN (1999). A single exposure to amphetamine is sufficient to induce long-term behavioral, neuroendocrine, and neurochemical sensitization in rats. J Neurosci 19: 9579-9586.

Venables PH (1964). Input dysfunction in schizophrenia. In: Maher BA (ed). Progress in Experimental Personality Research. Academic Press: New York. pp 1-47.

Ventura J, Nuechterlein KH, Lukoff D, Hardesty JP (1989). A prospective study of stressful life events and schizophrenic relapse. J Abnorm Psychol 98: 407-411.
Wallis GG, Mc HJ, Scott OC (1949). Acute psychosis caused by dextro-amphetamine. Br Med J 2: 1394.

Weiner IB (1964). Differential diagnosis in amphetamine psychosis. Psychiatr Q 38: 707-716.

Yui K, Goto K, Ikemoto S, Ishiguro T, Angrist B, Duncan GE et al (1999). Neurobiological basis of relapse prediction in stimulantinduced psychosis and schizophrenia: the role of sensitization. Mol Psychiatry 4: 512-523.

Zaborszky L (2002). The modular organization of brain systems. Basal forebrain: the last frontier. Prog Brain Res 136: 359-372.

Zaborszky L, Gaykema RP, Swanson DJ, Cullinan WE (1997). Cortical input to the basal forebrain. Neuroscience 79: 1051-1078.

Zahm DS (2000). An integrative neuroanatomical perspective on some subcortical substrates of adaptive responding with emphasis on the nucleus accumbens. Neurosci Biobehav Rev 24: 85-105.

Zmarowski A, Sarter M, Bruno JP (2005). NMDA and dopamine interactions in the nucleus accumbens modulate cortical acetylcholine release. Eur J Neurosci 22: 1731-1740. 